\title{
A Review of Twinning in Niger Delta Region, Nigeria
}

\author{
Ikeanyi Eugene Maduabuchukwu ${ }^{*}$, Ikobho Ebenezer Howell \\ Department of Obstetrics and Gynecology, Niger Delta University, Amassoma, Nigeria \\ Email address: \\ abuchikeanyi@yahoo.com (I. E. Maduabuchukwu), Ikobhoebenezer@yahoo.com (I. E. Howell) \\ ${ }^{*}$ Corresponding author
}

\section{To cite this article:}

Ikeanyi Eugene Maduabuchukwu, Ikobho Ebenezer Howell. A Review of Twinning in Niger Delta Region, Nigeria. Clinical Medicine Research. Vol. 7, No. 1, 2018, pp. 18-25. doi: 10.11648/j.cmr.20180701.13

Received: February 7, 2018; Accepted: February 25, 2018; Published: March 22, 2018

\begin{abstract}
Background: Twin pregnancy is as fascinating as it is high risk and its epidemiology is globally more dynamic in the recent times. It is associated with increase maternal morbidities, fetal wastage and neonatal morbidities and mortality. Objectives: To determine the current incidence, assess the trend and investigate maternal and perinatal outcomes and influencing factors of twinning. Methods: For this case control study, data was collected on twin pregnancies; the study group and singleton pregnancies; the control group between January 2009 and December 2016 at a missionary Hospital in southsouth Nigeria. EPI INFO and INSTAT statistical software were used for analyses and Fisher's exact test for tests of statistical associations setting the statistical significance at $<.05$. Results: Among 8769 deliveries were 207 pairs of twins, a twinning incidence of $2.4 \%$ or 1 in 42 with an upward trend in incidence. Twin mothers were relatively older with those aged 30-34 years $(41.2 \%)$ as the modal age group, less literate and less likely to have prenatal care. They were more prone to anemia, caesarean birth, Postpartum hemorrhage, gestational hypertension and blood transfusion $(\mathrm{P}<0.05)$. Mean gestational age and birth weight of twins were $35.5 \pm 3.8$ weeks and $2352.9 \pm 746.4 \mathrm{gm}$ respectively. The twins were associated with increased preterm births (OR 28.1, $\mathrm{P}<0.001$ ), Low birth weight (OR 15.6-24.1, $\mathrm{P}<0.001$ ), perinatal death $(\mathrm{OR} 3.6, \mathrm{P}<0.001)$, birth asphyxia (OR 2.9-5.9, $\mathrm{P}<0.01$ ) and Special Care Baby Unit admission (OR 9.8-12.5, $\mathrm{P}<0.001)$. About 7 (66.2\%) and 3 (31.4\%) of every 10 first twins were in cephalic and breech presentation respectively with cephalic/cephalic (44.0\%) the leading paired presentations. Conclusion: There was high and increasing incidence of twinning in this population. Twin pregnancy is associated with increased maternal morbidity and perinatal morbidity and mortality. To improve twinning outcome will require quality obstetric and perinatal care.
\end{abstract}

Keywords: Multiple Pregnancy, Twin Gestation, Maternal, Outcome, Perinatal, Benin City

\section{Introduction}

Twin pregnancy is a high risk pregnancy and its epidemiology is fast changing globally in the recent times. It is associated with increase maternal morbidities, fetal wastage and neonatal morbidities and mortality. To the mother there is increased emotional and physical stress and to the family and health system increased financial burden. The recent global upward trend in twining rates is part of the general increase in rates of multifetal pregnancy majorly due to the fast increasing fertility therapies; assisted reproductive technologies (ART) and ovulation induction drugs coupled with the increasing age of women at reproduction. The incidence of twin pregnancy is highest among the black population. In Africa among low and mid income countries the rates are as high as 36-42 per 1000 births with Nigeria leading at $4.2 \%$ [1]. In fact recent data indicate that very high natural twinning rates of above 18 per thousand births are found in most central-African countries and very low rates of 6-9 per thousand births in the whole South and South-East Asia as in Latin America [2]. Within Africa, Nigeria has the leading incidence with the highest concentration among the Yoruba in Southwest Nigeria with rates of 49-54 per 1000 deliveries [3]. The rate is intermediate with incidence of 12 in 1000 deliveries among the Caucasians and lowest at 4 per 1000 deliveries among the Asian populations [3]. In USA the recent twinning rate was 33.9 per 1000 total births with the highest rate of 40 among the Non-Hispanic black compared with Non-Hispanic white and Hispanic white with 36.7 and 24.1 respectively [4]. 
Racial and geographical variation in twinning incidence is a reflection of the factors influencing dizygotic twinning that results from multiple ovulation and fertilization. Dizygotic (fraternal) twinning occurs spontaneously from 4 per 1000 deliveries in Asian population through 12 in 1000 deliveries in Caucasians to 54 per 1000 in black population in Nigeria [3]. On the other hand, the monozygotic (identical) twinning results from splitting of a single embryo early in its development, is relatively rare and constant at about 3.9 per 1000 deliveries in all populations [3, 5-6] though twinning seems to be highly influenced by multiple embryo transfer in ART. The risk of dizygotic twinning rises with maternal age until age 38 and thereafter declines again [5-6]. Other factors influencing the rate of dizygotic twining are racial/ethnicity [2], familial or genetic factor in female lineage [2, 5-7], parity [5-6], maternal height $[5,8]$, high body mass index (BMI) [5, 8], smoking [5], previous oral contraception [5].

Compared with singleton gestations, multiple gestations are more prone to complications [1, 4, 9 ]. For reasons of inherent biological factors, twinning has been associated with increased risk of preeclampsia and postpartum hemorrhage for the mother and preterm birth and low birth weight for the neonate $[1,2,4,10-11]$. These complications are made worse by social deprivation especially poor health services [1]. Twin pregnancy and its related data is best studied in relation to those on the singleton pregnancy. This study was therefore designed to examine the outcomes of twinning by comparing the outcome variables of twin with singleton deliveries.

A regular audit of multiple pregnancies will provide up to date data on twinning in different populations like Nigeria. It is expected that the results of such study would provide information on the trend of twinning, leading maternal and perinatal complications in twin pregnancy. This will help in health care policies and planning in the contemporary obstetric practice.

Naturally Nigeria is globally rated one of the countries with the highest incidences of twinning. ART services are increasingly available in Nigeria albeit costly. A combination of these factors necessitates regular updating of data from Nigerian regions and this informed the interest in this study to measure the incidence, trend and evaluate the maternal and fetal outcomes and related factors of twinning in oil-rich Niger Delta region of Nigeria.

\section{Materials \& Methods}

This was a case control analytical observational study that took place at St Philomena Catholic Mission Hospital Benin City Edo State south-south Nigeria. Benin City is the capital of Edo state one of the oil rich states of Niger Delta region of Nigeria. It is home to multiethnic population predominated by the indigenous Bini and Esan, and non-indigenous residents across other states and outside Nigeria. The residents of the city are predominantly civil servants and traders. The long serving hospital is a top-tier mission hospital located at the center of Benin City and serves as a referral center to various other health facilities within and outside the city. It has over a thousand annual delivery rate.

The labor ward and theatre records of all the deliveries that occurred from January 2009 to December 2016 were retrospectively reviewed. Each twin pregnancy was recruited into the study group and the next two singleton deliveries were recruited into the control subgroup. With the aid of the case files retrospective review of each of the subjects was done for maternal sociodemographic characteristics, details of the pregnancies; mode of delivery, fetal outcomes, maternal complications and the related factors. All the cases of previous caesarean section, all abortions and incomplete records were excluded otherwise all the twin deliveries $(\geq 24$ weeks gestation) were eligible and included in the final analysis. Ethical approval was obtained from the hospital Research and Ethical Committee (REC). There was no involvement of individual patient identifiers therefore consent from the subjects was not required. The main outcome variables measured were twinning incidence, perinatal variables; preterm births, stillbirth rate, perinatal deaths, low birth weight and maternal variables; caesarean section rate, obstetric hemorrhage, gestational hypertension, anemia.

The relevant data were extracted into the EPI INFO computer software and the statistical analysis performed with it. Statistical tests for associations were measured with the Fisher's exact test and reports were presented in percentages and Odd Ratio. Student's t-test was used to compare the means. Statistical significance was set at $\mathrm{P}<.05$ and $95 \%$ Confidence Interval (CI) exclusion of nullity of one.

The limitations of study were its hospital based and retrospective data while its strengths derive in its case control design and sample size.

\section{Results}

Table 1. Twin delivery by years.

\begin{tabular}{llll}
\hline Year & Total Delivery & Number Twin delivery & $\begin{array}{l}\text { Incidence / } \\
\mathbf{1 0 0 0} \text { births }\end{array}$ \\
\hline 2009 & 877 & 11 & 12.5 \\
2010 & 1012 & 27 & 26.7 \\
2011 & 924 & 21 & 22.7 \\
2012 & 785 & 12 & 15.3 \\
2013 & 789 & 16 & 20.3 \\
2014 & 1196 & 31 & 25.9 \\
2015 & 1518 & 46 & 30.3 \\
2016 & 1668 & 43 & 25.8 \\
Total & 8769 & 207 & 23.6 \\
\hline
\end{tabular}

There was a total of 207 twin deliveries resulting in 414 twin neonates in the reviewed period. The case file of three of the recorded twin deliveries could not be retrieved, a retrieval rate of 204/207 (98.6\%) and these were used for subsequent analyses.

Table 1 is a display of twin delivery by years. Of the 8769 total deliveries that took place at the center in the reviewed eight year period, $207(2.36 \%)$ were twin deliveries. The mean annual twin delivery rate was highest in 2015 and lowest in 2009; the first year of the reviewed period; a range 
of 12.5 to 30.3 twin deliveries per 1000 deliveries in this

$1.25 \%$ in 2009 to $2.58 \%$ in 2016 . data. Overall, there was $106.4 \%$ increase of twining rate from

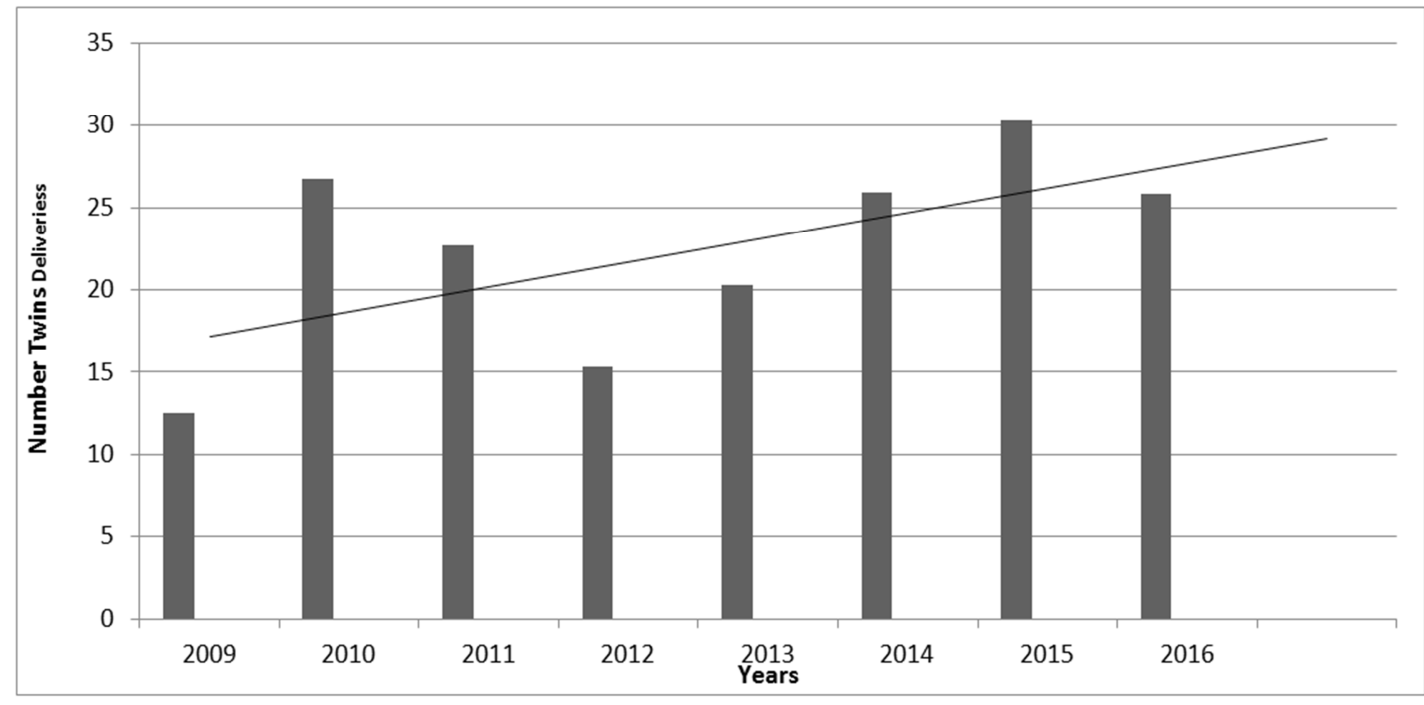

Figure 1. Trend of Twining in the Reviewed Period.

Figure 1 shows a graphic demonstration of the trend of twin deliveries in the reviewed period. Much as there was variability in the rates of annual twin deliveries, our data indicates an increasing pattern in twinning; an upward trend in the rates of twin deliveries over the study period.

Table 2. Sociodemographic profile of Subjects $(N=612)$.

\begin{tabular}{|c|c|c|c|c|c|}
\hline \multirow{2}{*}{ Variable } & \multirow{2}{*}{ Category } & \multirow{2}{*}{$\begin{array}{l}\text { Study group } \\
\mathbf{n}=204(\%) \\
\end{array}$} & \multirow{2}{*}{$\begin{array}{l}\text { Control group } \\
\mathrm{n}=408(\%) \\
\end{array}$} & \multirow{2}{*}{ OR $(95 \%$ CI $)$} & \multirow{2}{*}{ P-value } \\
\hline & & & & & \\
\hline \multicolumn{6}{|c|}{ Age (years) } \\
\hline & $<20$ & $2(1.0)$ & $5(1.2)$ & - & - \\
\hline & $20-24$ & $18(8.8)$ & $44(10.8)$ & - & - \\
\hline & $25-29$ & $68(33.3)$ & $152(37.3)$ & - & - \\
\hline & $30-34$ & $84(41.2)$ & $145(35.5)$ & - & - \\
\hline & $=/>35$ & $32(15.7)$ & $62(15.2)$ & - & - \\
\hline & Mean & $30.2 \pm 4.6$ & $29.6 \pm 4.6$ & & 0.13 \\
\hline \multirow[t]{4}{*}{ Parity } & 0 & $76(37.3)$ & $159(39.0)$ & - & - \\
\hline & $1-4$ & $125(61.3)$ & $240(58.8)$ & 1.1 & 0.66 \\
\hline & $\geq 5$ & $3(1.5)$ & $9(2.2)$ & 0.7 & 0.76 \\
\hline & Mean & $1.3 \pm 1.3$ & $1.1 \pm 1.2$ & - & 0.06 \\
\hline \multicolumn{6}{|l|}{ Education: } \\
\hline & $\leq$ Secondary & $138(67.6$ & $220(53.9)$ & $1.8(1.3-2.5)$ & $<0.001$ \\
\hline & >Secondary & $66(32.4)$ & $188(46.1)$ & & \\
\hline \multicolumn{6}{|c|}{ Booking status: } \\
\hline & Unbooked & 40 (19.6) & $30(7.4)$ & $3.1(1.9-5.1)$ & $<0.001$ \\
\hline & Booked & $164(80.4)$ & $378(92.6)$ & & \\
\hline \multicolumn{6}{|c|}{ Ethnic group: } \\
\hline & Bini & $109(53.4)$ & $163(40.0)$ & & \\
\hline & Esan & 40 (19.6) & $107(26.2)$ & & \\
\hline & Etsako & $2(1.0)$ & $17(4.2)$ & & \\
\hline & Hausa & $2(1.0)$ & $13(3.2)$ & & \\
\hline & Igbo & $28(13.7)$ & $80(19.6)$ & & \\
\hline & Yoruba & $16(7.8)$ & $24(5.9)$ & & \\
\hline & Others & $7(3.4)$ & $4(1.0)$ & & \\
\hline
\end{tabular}

From the Sociodemographic display of the participants in Table 2, the study group was on average older; $30.2 \pm 4.6$ vs.29.6 \pm 4.6 but the 0.6 years difference was not statistically significant $(\mathrm{t}=1.52, \mathrm{P}=0.13)$. Close to two thirds $(56.9 \%$ vs.
$50.7 \%$ ) of the study group were 30 years or older. The study group was more than thrice more likely to be unbooked. The observed difference was statistically significant (OR 3.1, $\mathrm{P}<0.001$ ). In addition, the study group was close to twice 
more likely to be less educated. The observed difference was statistically significant (OR $1.8, \mathrm{P}<0.01)$. They were also of higher parity though the observed difference was not significant. More than half (53.4\%) were of indigenous Bini ethnicity.

Table 3. Maternal outcomes by Subgroups $N=612(\%)$.

\begin{tabular}{|c|c|c|c|c|}
\hline Outcome variable & Study group & Control group & Odd Ratio (95\% CI) & P-value \\
\hline & $n(\%)=204$ & n $(\%)=408$ & & \\
\hline Caesarean birth & $118(57.8)$ & $126(30.9)$ & $3.1(2.2-4.4)$ & $<0.001$ \\
\hline $\mathrm{PIH} / \mathrm{PE}$ & $49(24.0)$ & $61(15.0)$ & $1.8(1.2-2.7)$ & 0.01 \\
\hline PPH & $24(11.8)$ & $22(5.4)$ & $2.3(1.3-4.3)$ & 0.009 \\
\hline $\mathrm{APH}$ & $10(4.9)$ & $21(5.1)$ & 0.9 & 1.00 \\
\hline Transfusion & $16(7.8)$ & $3(0.7)$ & $11.5(3.3-39.9)$ & $<0.001$ \\
\hline Mean EBL (ml) & $606.4 \pm 515.4$ & $410.7 \pm 298.3$ & - & $<0.001$ \\
\hline
\end{tabular}

Table 3 is a display of maternal outcomes. The study group was more than thrice more likely to deliver through caesarean section and this was statistically significant (OR 3.1, $\mathrm{P}<0.001)$. They were also significantly about twice $(\mathrm{OR}=1.8 \mathrm{CI}$ : $1.2-2.7)$ more likely to suffer gestational hypertension. Similarly, the study group was more than double (OR=2.1, CI: 1.4-3.2) more likely to have anemia and the observed difference was also statistically significant.
They were significantly more than twice more prone to postpartum hemorrhage and had approximately $200 \mathrm{ml}$ mean estimated blood loss more than the control counterparts $(p<0.001)$. The study group was therefore about twelvefold more prone to blood transfusion. Again the observed difference was statistically significant (OR 11.5 CI: 3.3-39.9, $\mathrm{p}<0.001)$.

Table 4. Perinatal Outcomes stratified by Subgroups $N=816$.

\begin{tabular}{|c|c|c|c|c|c|}
\hline \multirow{3}{*}{ Outcome variable } & \multicolumn{2}{|c|}{ Study group $N(\%)=408$} & \multirow{3}{*}{ Control group $N(\%)=408$} & \multirow{3}{*}{ OR $(95 \%$ CI $)$} & \multirow{3}{*}{ P-value } \\
\hline & \multirow{2}{*}{$\begin{array}{l}\text { Twin-1 } \\
\text { n (\%) }=204\end{array}$} & \multirow{2}{*}{$\begin{array}{l}\text { Twin-2 } \\
\text { n }(\%)=204\end{array}$} & & & \\
\hline & & & & & \\
\hline Live birth & $194(95.1)$ & $183(89.7)$ & $398(97.5)$ & $0.3(0.2-0.6)$ & $<0.001$ \\
\hline $\begin{array}{l}\text { Extremely preterm } \\
(<28 \text { weeks }) \text { : }\end{array}$ & $10(4.9)$ & $10(4.9)$ & 0 & - & - \\
\hline $\begin{array}{l}\text { Very preterm } \\
\text { (<32weeks): }\end{array}$ & $18(8.8)$ & $18(8.8)$ & $3(0.7)$ & $13.1(3.9-42.8)$ & $<0.001$ \\
\hline Mild preterm & & & & & \\
\hline (<37weeks): & $74(36.3)$ & $74(36.3)$ & $11(2.7)$ & $20.5(10.9-38.7)$ & $<0.001$ \\
\hline$\geq 37$ weeks & $90(44.1)$ & $90(44.1)$ & $285(69.9)$ & $0.3(0.3-0.5)$ & $<0.001$ \\
\hline$>40$ weeks & $12(5.9)$ & $12(5.9)$ & $109(26.7)$ & $0.2(0.1-0.3)$ & $<0.001$ \\
\hline Mean GA & $35.5 \pm 3.8$ & $35.5 \pm 3.8$ & $38.5 \pm 2.9$ & - & $<0.001$ \\
\hline Preterm $(<37)$ & $102(50.0)$ & $102(50.0)$ & $14(3.4)$ & - & $<0.001$ \\
\hline Mean BW(gm) & $2422.1 \pm 751.8$ & $2283.7 \pm 734.4$ & $3303.5 \pm 571.8$ & - & $<0.001$ \\
\hline LBW & $91(44.6)$ & $113(55.4)$ & $20(4.9)$ & $19.4(11.9-31.7)$ & $<0.001$ \\
\hline SGA & $31(15.2)$ & $33(16.2)$ & $15(3.8)$ & $4.9(2.7-8.7)$ & $<0.001$ \\
\hline Congenital anomaly & 0 & $2(1.0)$ & $2(0.5)$ & - & - \\
\hline Early neonatal death & $2(1.0)$ & $4(2.0)$ & $1(0.25)$ & 6.1 & 0.12 \\
\hline Stillbirths & $10(4.9)$ & $21(10.3)$ & $10(2.5)$ & $3.3(1.6-6.8)$ & 0.001 \\
\hline Postdate & $12(5.9)$ & $12(5.9)$ & $109(26.7)$ & $0.2(0.1-0.3)$ & $<0.001$ \\
\hline Macrosomia & $2(1.0)$ & 0 & $41(10.0)$ & $0.04(0.01-0.18)$ & $<0.001$ \\
\hline $\mathrm{A} / \mathrm{S} 5 \min <7$ & $18(8.8)$ & $33(16.2)$ & $13(3.2)$ & $4.3(2.3-8.1)$ & $<0.001$ \\
\hline SCBU admission & $26(12.7)$ & $32(15.7)$ & $6(1.5)$ & $11.1(4.7-26.1)$ & $<0.001$ \\
\hline Perinatal death & $12(5.9)$ & $25(12.3)$ & $11(2.7)$ & $3.6(1.8-7.2)$ & 0.001 \\
\hline
\end{tabular}

Table 4 shows the perinatal outcomes stratified by subgroups. The mean gestational age at delivery of twins and singletons in this data were $35.5 \pm 3.8$ weeks and $38.5 \pm 2.9$ weeks respectively. Compared with the singleton births, the mean gestational age difference at birth of three weeks was statistically significant $(\mathrm{P}<0.001)$. Twins were significantly $50 \%$ vs. $3.4 \%$ more likely to be delivered preterm (OR 28.1, CI: $15.5-51.3, \mathrm{P}<0.001)$. The twins were $4.9 \%$ vs. $0.0 \%$ more likely to be born extremely preterm (less than 28 completed weeks), $8.8 \%$ vs. $0.7 \%$ very preterm (up to 28 but less than 32 completed weeks) and $36.3 \%$ vs. $2.7 \%$ preterm (up to 32 but less than 37 completed weeks). The twins were about $70 \%$ less likely to be a live birth relative to singleton pregnancy. This was statistically significant $(\mathrm{P}<0.01)$. Jointly, the twins weighed on average $2352.9 \pm 746.4 \mathrm{gm}$ about 950.6 grams less than the singleton newborns at birth and this was 
statistically significant $(\mathrm{P}<0.001)$. Comparatively, the first and the second twins on average respectively weighed 881.4 grams and 1019.8grams less than the singleton neonates. The observed differences were statistically significant $(\mathrm{P}<0.0001)$. The first and the second twins were respectively 16 and 24 times more likely to be born low birth weight and when combined, they were more than nineteen folds 19.4 (11.9-31.7) so and the observed differences were statistically significant $(\mathrm{P}<0.001)$. Combined, the twins were more than thrice $31 / 408(7.6 \%)$ vs. $10 / 408(2.5 \%)$ more likely to suffer intrauterine death. The observed difference was statistically significant (OR 3.3, CI: 1.6-6.8, $\mathrm{P}<0.001$ ). Compared with singleton birth, the first Twin was twice more likely to suffer intrauterine death but this was not statistically significant (OR 2.0, $\mathrm{P}=0.15$ ) unlike the second twin that was close to fivefold more likely to be born stillbirth and this was statistically significant (OR: 4.6, CI: 2.1-9.9, $\mathrm{P}<0.001$ ). The twins were relatively three (OR 2.9CI: $1.4-6.1$ ) to six folds (OR 5.9 CI: 3.0-11.4) more likely to have Apgar score of less than 7 at 5 minute. This was statistically significant $(\mathrm{P}<0.01)$. In addition, the twins were about eleven folds and between the first and second twins ten (OR 9.8, CI:4.0-24.2) to thirteen folds (OR 12.5, CI: 5.1-30.4) more likely to be admitted in special care baby unit and this was statistically significant $(\mathrm{P}<.001)$. A total of $12 / 204,25 / 204$ and $11 / 408$ neonates respectively suffered perinatal death; perinatal mortality rates of 58.8, 122.5 and 27.0 per 1000 total births for the first and the second twins and the control neonates respectively (OR 2.3-5.0, CI: 2.4-10.5, $\mathrm{P}<0.001$ ). When the 408 twins were compared with the singleton counterparts, the twins were close to fourfold $(9.1 \%$ vs. $2.9 \%)$ more likely to suffer perinatal death (OR 3.6, CI: 1.8-7.2, $\mathrm{P}<0.001$ ). Compared to other causes, prematurity contributed most to twins perinatal deaths; $35 / 204(17.2 \%)$ of preterm twins vs.2/204 $(1.0 \%)$ of term twins suffered perinatal death. The observed difference was significant (OR: 20.9, CI: 5.0-88.3, $\mathrm{P}<0.001)$. Overall, $35 / 37$ (94.6\%) of the twin perinatal deaths was prematurity-related death. The twin neonates delivered to the unbooked mothers were more than fivefold $19 / 80$ $(23.8 \%)$ vs. $18 / 328(5.5 \%)$, more prone to perinatal death. The observed difference was statistically significant (OR 5.4: CI: $2.7-10.8, \mathrm{P}<0.001)$. The female-male sex ratio were 1.1 and 1.04 for twins and singleton neonates respectively.

Table 5. Outcomes of Twin-1 versus Twin-2.

\begin{tabular}{lllll}
\hline \multirow{2}{*}{ Features } & Twin-1 & Twin-2 & OR (95\% CI) & P-value \\
\cline { 2 - 3 } & $\mathbf{N}(\mathbf{\%}) \mathbf{2 0 4}$ & $\mathbf{N}(\mathbf{\%}) \mathbf{2 0 4}$ & & 1.00 \\
\hline Caesarean birth: & $117(57.4)$ & $118(57.8)$ & 1.0 & 0.04 \\
LBW & $91(44.6)$ & $113(55.4)$ & $0.6(0.4-0.9)$ & 0.68 \\
$<1000$ gms & $11(5.4)$ & $14(6.9)$ & 0.8 & 0.33 \\
$<1500$ gms & $15(7.4)$ & $17(8.3)$ & 0.6 & 0.10 \\
$<2500$ & $65(31.9)$ & $82(40.2)$ & 0.7 & 0.06 \\
$<4000$ gms & $111(54.4)$ & $91(44.6)$ & 1.5 & - \\
$\geq 4000$ & $2(1.0)$ & 0 & - & 0.04 \\
A/S 5min<7 & $18(8.8)$ & $33(16.2)$ & $0.5(0.3-1.0)$ & 0.48 \\
SCBU Admission: & $26(12.7)$ & $32(15.7)$ & 0.8 & 0.06 \\
Stillbirth & $10(4.9)$ & $21(10.3)$ & $0.5(0.2-1.0)$ & 0.06 \\
Mean BW(gm) & $2422.1 \pm 751.8$ & $2283.7 \pm 734.4$ & - & 0.89 \\
SGA & $31(15.2)$ & $33(16.2)$ & 1.0 & - \\
Macrosomia & $2(1.0)$ & 0 & - & 0.7 \\
ENND & $2(1.0)$ & $4(2.0)$ & - & 0.04 \\
Perinatal death: & $12(5.9)$ & $25(12.3)$ & $0.4(0.2-0.9)$ & \\
\hline
\end{tabular}

Further subgroup analysis of the twin sets in Table 5 comparing the outcomes of the twins shows that first twins are significantly less likely to suffer low birth weight (OR 0.6, CI:0.4-0.9) and birth asphyxia (OR 0.5, CI:0.3-0.9). Comparatively, the first twins were more than $50 \%$ less likely to suffer perinatal death. The observed difference was significant (OR 0.4, CI: 0.2-0.9, $\mathrm{P}=0.04$ ).

Though the first twins were less likely to be admitted into special care baby unit and to suffer early neonatal death and stillbirth, none of these three observed differences was statistically significant $(\mathrm{P}>0.05)$. The first twins were on average $138.4 \mathrm{gm}$ heavier than the second twins at birth, again, the observed difference was not significant. A larger proportion; $53 \%$ of the twins were of same-sex pairs either females $29.1 \%$ or males $23.9 \%$ while the rest were of discordant sex pairs female/male $27.4 \%$ and male/female $19.7 \%$. The female twins were the leading twin in majority; $56.5 \%$ of the cases. 


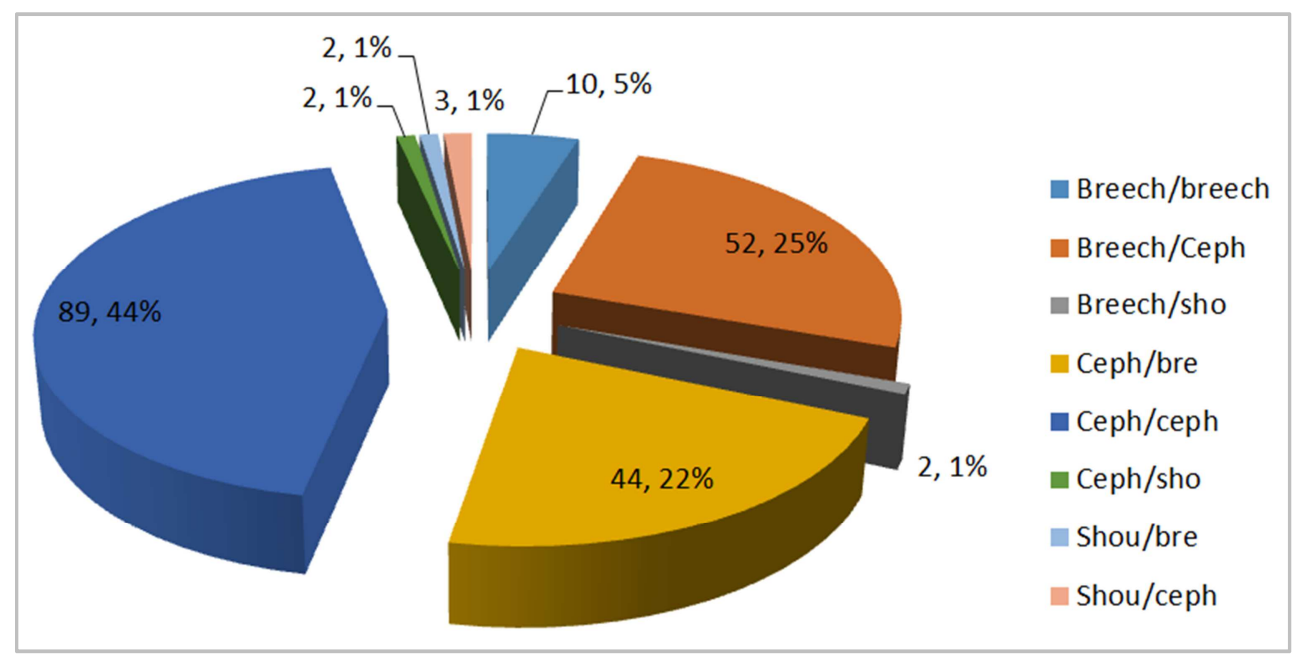

Figure 2. Presentation of Twin Pairs at Delivery $n=204$ Pairs.

Figure 2 shows the presentation of the twin pairs. The largest proportion of the twin sets were in cephalic/cephalic presentation $(44.0 \%)$ followed by breech/cephalic $(25.0 \%)$ and cephalic/breech $(22.0 \%)$ in that descending order. In $135 / 204(66.2 \%)$ of cases, the leading twins were in cephalic presentation and breech in $64 / 20431.4 \%$ of cases.

\section{Discussion}

This study highlighted the incidence, trend and obstetric importance of twin pregnancy as relate to maternal and fetal outcomes. This data demonstrated high and rising incidence of twin pregnancy over the study period in the center. Secondly the data demonstrated associated increase prenatal, intrapartum and postpartum morbidity in twin mothers as well as fetal and neonatal morbidity and mortality.

The 24 per 1000 incidence of twinning in this data is higher than 13.1 per thousand global low and middle income countries average figure [2]. This was comparable to similar findings of 25.3-26.5 per 1000 reported by previous researchers in this region [12-14], 23 per 1000 in Jos and Kano north central and North-west Nigeria respectively [1516] and 22 per 1000 from a missionary hospital in Enugu; southeast Nigeria [17]. However, the figure appeared higher than 14.4 per 1000 in northeast [18] and lower than the mean finding of 40.2 per 1000 with a range of 22.1-46.5from a four urban facility multicenter study in south-west Nigeria [19], 42 per thousand from a tertiary hospital in South-east [20] and 32.5 in 1000 from Abuja [21]. Abuja is the Nigerian fast growing Federal Capital Territory with wide multiethnic and multinational residents. The 2014 twin birth rate was 33.9 per 1,000 births, a new high for the United States [4]. Recent twinning rates from developed countries are substantially influenced by high rates of ART unlike in poorer economies where the service is scarce or unaffordable to many where it exists. The high incidence of twinning observed in our data can be ascribed to the inherent racial factor in the black populations, increased maternal age and possibly the increasing impact of assisted reproduction services in the setting.

The twin mothers were older at a mean age of $30.2 \pm 4.6$ and the most frequent age group was 30-34 years accounting for two fifths of twin mothers. This is consistent with reports from similar studies [20-22]. This seems to agree to the documented evidence associating increased maternal age with twinning. It is evident that as maternal age advances there is a relative increase in the levels of follicle stimulating hormone [3] that results in increased risk of multiple ovulations. This however tends to decline in the late reproductive period as evidenced in this data corroborated by other reports [5-6, 2, 19].

There was more than a triple caesarean section rate at $57.8 \%$ in this data relative to singleton deliveries and this was comparable to the rates reported by other researchers $[13,15,20,23]$ and higher than $27.3 \%$ in another report [21], lower than $64.9-69.7 \%$ reported by researchers in Europe [24]. The increased caesarean rate in this data was attributable to the high incidence of non-cephalic presentation of the leading twins, poor fetal conditions and increased cases of confounding gestational hypertension. There is increasing evidence to support elective caesarean delivery to prevent the fivefold increased risk of intrapartumrelated death of second twin [3]. This becomes more important in deliveries at term when unlike preterm births there is evidence of significant increase in delivery-related perinatal death of second twins mostly from anoxia caused in most cases by mechanical problems like cord prolapse or malpresentation at vaginal delivery of the first twin [25]. This implies a low threshold for elective caesarean section to prevent vaginal-caesarean birth that is associated with increased neonatal deaths whether in cephalic-cephalic presenting twin pairs or worst in cephalic-breech pairs. Again to mitigate delivery-related perinatal deaths, late or peripartum obstetric scan has a role to define the presentations of the twins to expedite delivery process.

The leading adverse neonatal outcome in our data was preterm delivery in $50 \%$ of all the twin deliveries with its associated prematurity. This was comparable to $50.6 \%$ 
reported by other researchers from this region [13], higher than $39.7 \%$ from Abuja [21], 41\% from south-east [20] and South west Nigeria [26] Our figures are however, lower than $63.07-62.50 \%$ by Dera et al [24].

The mean gestational age at delivery of 35.5 weeks was lower than 36.2 weeks and 36.5 weeks from Southeast and southwest Nigeria respectively [20,26] and comparable to 35.7-35.9 weeks by Dera et al [24] and 35.3 weeks from national population based data in USA [27].

The perinatal mortality rate in our data was 90.7 per 1000 births about fourfold relative to 29 per 1000 for single births at the center in the study period consistent with another report [3]. This was comparable to 85.4- 91 per 1000 births reported by Nwobodo etal [18] and Mutihir etal [15], lower than 207 per 1000 births reported by Abassiatai et al [13] and 158.5 per 1000 by Ibrahim et al [22]. The leading cause of perinatal death in this data was fetal prematurity contributing $94.6 \%$ of perinatal deaths. This was made worst when further complicated by increased rates of low birth weight and intrauterine growth restriction as in this data. In addition there was significant failure to access prenatal care in this data, though we had no data on this; possibly coupled with late presentation in labor that is commonplace in our setting. Prematurity is the leading cause of perinatal mortality both in developed and worse in developing countries like Nigeria with limited neonatal services. This is worst observed in multifetal deliveries especially when related to single deliveries as in our data.

The role of prenatal care in the improvement of perinatal outcome in twin pregnancy cannot be overemphasized as evidenced in this study. Lack of prenatal care more than fivefold contributed to perinatal deaths in this data.

The most favored presentations of the twin pairs from this data were cephalic-cephalic at $44 \%$ comparable to $47-48.8 \%$ by other researchers $[15,18,21]$. Cephalic presenting fetus in absence of other confounding factors favors vaginal delivery and better outcome compare to other presentations. In satisfactory fetal growth and wellbeing, the mode of delivery in twin pregnancy is mostly decided on the presentation of the first twin. In such cases, cephalic presenting first twin favors vaginal delivery and any other presentation caesarean delivery. The presentation of the second twin becomes relevant following the delivery of the first twin. However it is in the literature that vertex-vertex twin pair vaginally delivered and vertex-breech pair abdominally delivered have the lowest risk of neonatal death [23]. The female to male sex ratio of the twins was 1.1 and this was consistent to the findings of Akaba et al and comparable to an earlier report of male to female of 1.05 from the setting [28] and differs from male to female ratio of 1.2 reported by Nwobodo etal. [18]

We had no information on chorionicity or use of assisted reproductive technologies $[1,29]$ or timing of the presentation of the parturient in labor which are known to have a significant impact on fetal and neonatal outcomes. Retrospective data is fraught with the limitation of the proof of causality. However, the study derives its strength from its case control design and sample size.

\section{Conclusions}

The rate of twinning in this population is high with an upward trend. Twining is associated with increased rates of caesarean section, neonatal prematurity as well as low birth weight and perinatal mortality mostly from neonatal prematurity.

\section{Recommendations}

Improving maternity care such as quality prenatal care and labor supervision with timely safe caesarean section and quality neonatal services will improve the outcome of the currently rising rates of twin pregnancy.

\section{References}

[1] Vogel JP, Torloni MR, Seuc A, Betrán AP, Widmer M, Souza JP, Merialdi M. Maternal and Perinatal Outcomes of Twin Pregnancy in 23 Low- and Middle-Income Countries PLoS ONE 2013; 8 (8): e70549. doi:10.1371/journal.pone.0070549.

[2] Smits J, Monden C Twinning across the Developing World. Plos One 2011; 6: e25239 doi:10.1371/journal.pone.0025239.

[3] Fisk NM. Multiple Pregnancy. Dewhurst Textbook of Obstetrics and Gynaecology. Edmonds DK eds, $7^{\text {th }}$ edition, Blackwell Publishers 2007; 166-176.

[4] Hamilton BE, Martin JA, Osterman MJ, Curtin SC, Mathews TJ. Births: Final Data for 2014. Natl Vital Stat Rep.2015; 64 (12):1-64.

[5] Hoekstra C, Zhao ZZ, Lambalk CB, Willemsen G, Martin NG, Boomsma DI, Montgomery GW. Dizygotic twinning. Human Reprod Update. 2008; 14 (1): 37-47. [PubMed].

[6] Bortolus R, Parazzini F, Chatenoud L, Benzi G, Bianchi MM, Marini A. The epidemiology of multiple births. Human Reprod Update. 1999; 5 (2):179-187. [PubMed].

[7] Lichtenstein P, Olausson PO, Kallen AJ. Twin births to mothers who are twins: A registry based study. BMJ. 1996; 312: 879-881. [PubMed].

[8] Basso O, Nohr EA, Christensen K, Olsen J. Risk of twinning as a function of maternal height and body mass index. JAMA. 2004; 291:1564-1566. [PubMed].

[9] Bush MC, Pernoll ML. Multiple pregnanacy. In: DeCherny AH, Nathan L, Goodwin TM, Laufer N, editors. Currrent diagnosis and treatment, obstetrics and gynecology. 10th ed. New York, NY: McGraw Hill; 2007. pp. 301-10.

[10] Aisien A, Olarewaju R Twins in Jos Nigeria: a seven-year retrospective study. Med Sci Monit 2000; 6: 945-50.

[11] Obiechina N, Okolie V, Eleje G Twin versus singleton pregnancies: the incidence, pregnancy complications, and obstetric outcomes in a Nigerian tertiary hospital. Int J Womens Health 2011: 227-230.

[12] Onyiriuka AN Twin delivery: comparison of incidence and foetal outcome in two health institutions in Benin city, Nigeria. Nig Q J Hosp Med. 2009; 19 (1):1-5. 
[13] Abasiattai AM, Umoiyobo AJ, Utuk NM, Shittu DG. Incidence and mode of delivery of twin pregnancies in Uyo, Nigeria. Niger Med J 2010; 51:170-2.

[14] Bassey EA, Abasiattai AM, Udoma EJ, Asuquo EE. Outcome of twin pregnancy in Calabar, Nigeria. G J Med Sci. 2004; $3: 13-15$.

[15] Muthir JT, Pam VC. Obstetric outcome of twin pregnancies in Jos, Nigeria. Niger J Clin Pract. 2007; 10:15-8. [PubMed].

[16] Sunday-Adeoye I., Twomey E. D., Egwuatu V. E. A 20-year review of twin births at Mater Misericordiae Hospital, Afikpo, South Eastern, Nigeria. Nig J Clin Pract 2008; 11 (3): 231234.

[17] Attah RA, Mohammed Z, Gobir M. A Review of twin deliveries in Aminu Kano Teaching Hospital, North-West, Nigeria. Niger J Basic Clin Sci 2014; 11:3-7.

[18] Nwobodo EI, Bobzom DN, Obed J. Twin births at University of Maiduguri Teaching Hospital: incidence, pregnancy complications and outcome. Niger J Med. 2002; 11:67-9. [PubMed].

[19] Akinboro A, Azeez MA, Bakare AA. Frequency of twining in southwest Nigeria. Indian J Hum Genet 2008; 14 2):41-47.

[20] Nwankwo TO, Aniebue UU, Ezenkwele E, Nwafor MI. Pregnancy outcome and factors affecting vaginal delivery of twins at University of Nigeria Teaching Hospital, Enugu. Niger J Clin Pract 2013; 16:490-5.

[21] Akaba GO, Agida TE, Onafowokan O, Offiong RA, Adewole ND. Review of Twin Pregnancies in a Tertiary Hospital in Abuja, Nigeria. J Health Popul Nutr 2013; 31 (2):272-7.
[22] Isa Ibrahim, Abisoye Oyeyemi, Abhulimen Obilahi. Twin pregnancies in the Niger Delta of Nigeria: a four-year review. IntJ Womens Health 2012; 4: 245-249. Doi:10.2147/IJWH. S31350.

[23] Kontopoulos EV, Ananth CV, Smulian JC, Vintzileos AM. The impact of route of delivery and presentation on twin neonatal and infant mortality: a population-based study in the USA, 1995-97. J Matern Fetal Neonatal Med. 2004; 15: 219 24. [PubMed].

[24] Dera A, Breboorowicz GH, Keith L. The mode of delivery in twin pregnancy part 2 maternal outcome. Arch Perinat Med 2008; 14:7-14.

[25] Smith GC, Pell JP, Dobbie R. Birth order, gestational age, and risk of delivery related perinatal death in twins: retrospective cohort study. Br Med J 2002; 325, 1004.

[26] Kuti O, Owolabi AT, Fasuba OB. Outcome of twin pregnancy in a Nigerian Teaching Hospital. Trop. J Obstet Gynaecol $2006 ; 23: 132-5$.

[27] Martin J. A., Hamilton B. E., Sutton P. D. Ventura SJ, Menacker F, Munson ML Births: final data for 2002 Natl. VitalStat. Rep.2003, 52 (10):1-113.

[28] Onyiriuka AN, Ikeanyi EM. Sex Ratio at Birth: A Retrospective Audit of the Birth Records of a Nigerian Hospital. NJOG 2015; 19 (1):85-88.

[29] Kapoor M Epidemic of plurality and contributions of assisted reproductive technology therein. Am J Med Genet C Semin Med Genet 2009; 15: 128-135. 